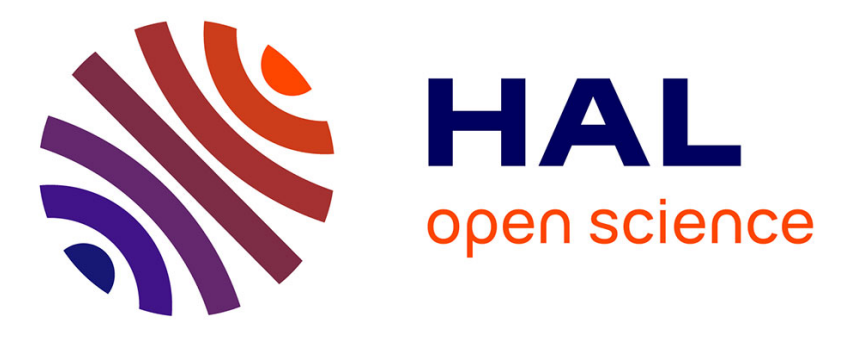

\title{
Conjugate ground and multisatellite observations of compression-related EMIC Pc1 waves and associated proton precipitation
}

\author{
M. E. Usanova, I.R. Mann, Z.C. Kale, I.J. Rae, R. D. Sydora, M. Sandanger, \\ Finn Søraas, K.-H. Glassmeier, Fornacon K.H., H. Matsui, et al.
}

\section{To cite this version:}

M. E. Usanova, I.R. Mann, Z.C. Kale, I.J. Rae, R. D. Sydora, et al.. Conjugate ground and multisatellite observations of compression-related EMIC Pc1 waves and associated proton precipitation. Journal of Geophysical Research Space Physics, 2010, 115 (A7), 10.1029/2009JA014935 . insu-03035968

\section{HAL Id: insu-03035968 https://hal-insu.archives-ouvertes.fr/insu-03035968}

Submitted on 2 Dec 2020

HAL is a multi-disciplinary open access archive for the deposit and dissemination of scientific research documents, whether they are published or not. The documents may come from teaching and research institutions in France or abroad, or from public or private research centers.
L'archive ouverte pluridisciplinaire HAL, est destinée au dépôt et à la diffusion de documents scientifiques de niveau recherche, publiés ou non, émanant des établissements d'enseignement et de recherche français ou étrangers, des laboratoires publics ou privés. 


\title{
Conjugate ground and multisatellite observations of compression- related EMIC Pc1 waves and associated proton precipitation
}

\author{
M. E. Usanova, ${ }^{1}$ I. R. Mann, ${ }^{1}$ Z. C. Kale, ${ }^{1,2}$ I. J. Rae, ${ }^{1}$ R. D. Sydora, ${ }^{1}$ M. Sandanger, ${ }^{3}$ \\ F. Søraas, ${ }^{3}$ K.-H. Glassmeier, ${ }^{4,5}$ K.-H. Fornacon, ${ }^{4}$ H. Matsui, ${ }^{6}$ P. A. Puhl-Quinn, ${ }^{6}$ \\ A. Masson, ${ }^{7}$ and X. Vallières ${ }^{8}$ \\ Received 28 September 2009; revised 31 January 2010; accepted 19 February 2010; published 15 July 2010.
}

[1] We present coordinated ground satellite observations of solar wind compressionrelated dayside electromagnetic ion cyclotron (EMIC) waves from 25 September 2005. On the ground, dayside structured EMIC wave activity was observed by the CARISMA and STEP magnetometer arrays for several hours during the period of maximum compression. The EMIC waves were also registered by the Cluster satellites for half an hour, as they consecutively crossed the conjugate equatorial plasmasphere on their perigee passes at $L \sim 5$. Simultaneously, conjugate to Cluster, NOAA 17 passed through field lines supporting EMIC wave activity and registered a localized enhancement of precipitating protons with energies $>30 \mathrm{keV}$. Our observations suggest that generation of the EMIC waves and consequent loss of energetic protons may last for several hours while the magnetosphere remains compressed. The EMIC waves were confined to the outer plasmasphere region, just inside the plasmapause. Analysis of lower-frequency Pc5 waves observed both by the Cluster electron drift instrument (EDI) and fluxgate magnetometer (FGM) instruments and by the ground magnetometers show that the repetitive structure of EMIC wave packets observed on the ground cannot be explained by the ultra low frequency (ULF) wave modulation theory. However, the EMIC wave repetition period on the ground was close to the estimated field-aligned Alfvénic travel time. For a short interval of time, there was some evidence that EMIC wave packet repetition period in the source region was half of that on the ground, which further suggests bidirectional propagation of wave packets.

Citation: Usanova, M. E., et al. (2010), Conjugate ground and multisatellite observations of compression-related EMIC Pc1 waves and associated proton precipitation, J. Geophys. Res., 115, A07208, doi:10.1029/2009JA014935.

\section{Introduction}

[2] Electromagnetic ion cyclotron (EMIC) waves are transverse plasma waves generated in the equatorial magnetosphere by energetic protons with temperature anisotropy $\left(T_{\perp}>T_{\|}\right)$and registered on the ground as Pc1-2 or IPDP (intervals of pulsations with diminishing periods) magnetic pulsations [e.g., Hayakawa et al., 1992, and references therein] in the frequency range between 0.1 and $5 \mathrm{~Hz}$. In the

\footnotetext{
${ }^{1}$ Department of Physics, University of Alberta, Edmonton, Alberta, Canada.

${ }^{2}$ Formerly at Z. C. Dent.

${ }^{3}$ Department of Physics and Technology, University of Bergen, Bergen, Norway.

${ }^{4}$ Institut für Geophysik und Extraterrestrische Physik, Technische Universität Braunschweig, Braunschweig, Germany.

${ }^{5}$ Max Planck Institute for Solar System Research, Katlenburg-Lindau, Germany.

${ }^{6}$ Space Science Center, University of New Hampshire, Durham, New Hampshire, USA.

${ }^{7}$ RSSD, ESTEC, Noordwijk, Netherlands.

${ }^{8}$ LPC2E/CNRS, Orléans, France.
}

Copyright 2010 by the American Geophysical Union. 0148-0227/10/2009JA014935 source region, the waves are expected to be left-hand polarized, corresponding to the sense of ion rotation around the magnetic field. Early theoretical studies have shown that the EMIC wave growth leads to the isotropization of the initially unstable proton distribution and consequent pitch angle scattering and loss of particles into the ionosphere [e.g., Cornwall, 1965]. This theory was supported by conjugate observations of localized precipitation of energetic protons (LPEP) at the ESRO satellite and IPDP pulsations conjugate to the satellite on the ground for the first time reported by Søraas et al. [1980]. Further connection between LPEP and EMIC waves has been studied using low Earth orbit polar NOAA satellites [see, e.g., Yahnin and Yahnina, 2007, and references therein]. Today, EMIC waves are considered as one of the important mechanisms affecting ring current dynamics, and their effects are included in global ring current numerical simulation models [e.g., Jordanova et al., 1997].

[3] Recent theoretical studies [e.g., Summers and Thorne, 2003] have shown that in the inner magnetosphere a resonant interaction with EMIC waves may also be important for $\mathrm{MeV}$ electron loss from the radiation belts, especially in regions of high plasma density and low magnetic field, e.g., 
outer regions of the quiet time plasmasphere. So far, there has been no direct experimental evidence supporting this hypothesis. However, Sandanger et al. [2007] reported simultaneous observations of collocated LPEP and relativistic electron precipitation in space and suggested that the latter might be the result of scattering of the electrons into the loss cone by EMIC waves even though they did not report any direct evidence of the presence of EMIC waves. Hence, EMIC waves are believed to be important not only for ring current but also for radiation belt dynamics.

[4] In order to incorporate the EMIC-related loss processes into global magnetospheric models, one needs to know the solar wind and magnetospheric conditions favorable for EMIC wave growth as well as the localization of the waves in the magnetosphere. Early studies have identified the plasmapause as a preferred region for EMIC wave generation, since the increasing number of cold ions leads to the drastic enhancement in the convective EMIC wave growth (which is inversely proportional to the Alfvén speed, $V_{\mathrm{A}}$ ) [e.g., Gendrin, 1975]. For example, EMIC waves were found to be preferentially excited along the duskside plasmapause during periods of enhanced magnetospheric convection [see, e.g., Summers et al., 1998]. The convection electric field may lead to the overall intensification of the ring current and also to the formation of anisotropic particle distributions, which may further aid wave growth.

[5] Further studies revealed other processes in the magnetosphere that lead to enhanced energetic ion temperature anisotropies. It was concluded that the waves could also be generated in the subsolar equatorial magnetosphere close to the magnetopause during magnetospheric compressions [Olson and Lee, 1983, Anderson and Hamilton, 1993, Denton et al., 2002] and in the cusp regions with peak occurrence near local noon and under different levels of geomagnetic activity [e.g., Menk et al., 1992]. Some observations of Pc1-2 pulsations in the cusp region have also been explained by injections of anisotropic ion populations generated in the equatorial magnetosphere and drifting westward [Hansen et al., 1992]. Recently, Usanova et al. [2008] reported observations of EMIC waves just inside the plasmapause (at $L \sim 6$ ) in the morning magnetic local time (MLT) sector during quiet geomagnetic conditions associated with intense magnetospheric compression due to enhanced solar wind dynamic pressure. The authors concluded that magnetospheric compressions might be an important source of radially localized EMIC waves in the dayside plasmasphere and suggested that this mechanism of EMIC wave generation might have wider importance for inner magnetosphere energetic particle dynamics.

[6] One of the mysteries of EMIC waves is their repetitive wave packet structure, which is often (but not always) observed on the ground. In spectrograms, they usually appear as distinct wave packets of rising frequency, regularly repeated with period of tens to hundreds of seconds [e.g., Mursula et al., 1997] and therefore are classified as structured Pcl pulsations or pearls. Pearls are the most common type of Pc1 pulsations observed at midlatitude and low-latitude magnetometer stations. Traditionally, structured Pc1s have been explained by a bouncing wave packet model [e.g., Jacobs and Watanabe, 1964]. In this model, a wave packet excited in the equatorial plane travels along the magnetic field line is reflected between conjugate hemispheres, and energy loss from incomplete ionospheric reflection is compensated by further wave growth as the wave packet recrosses the equator.

[7] However, there are a number of observations that do not agree with this theory. For example, the wave packet repetition period on the ground was found to be shorter than the realistic travel time of the wave packet between the hemispheres [see Mursula et al., 2001], the repetition period was observed to be the same on the ground and at offequatorial satellites [e.g., Mursula et al., 1999; Usanova et al., 2008], and the EMIC wave reflection coefficient from the ionosphere was estimated to be negligible [Erlandson et al., 1992]. EMIC wave Poynting flux measurements [Fraser et al., 1996; Loto'aniu et al., 2005] have also shown that the wave energy appears to be propagating away from the equator. An alternative theory suggested that EMIC repetitive structure might instead be due to modulation of EMIC wave growth and, consequently, wave power in the source region by the lower-frequency (Pc3-5) ULF waves [e.g., Fraser et al., 1992; Rasinkangas and Mursula, 1998; Loto'aniu et al., 2009].

[8] This paper is organized as follows. First, we discuss the ground-based and satellite instrumentation used for this study. Then we present observations of EMIC waves registered by ground-based and Cluster magnetometers during the interval of enhanced solar wind dynamic pressure. Further, we discuss the NOAA satellite observations of LPEP and consider the Cluster observations in the EMIC source region and show that they are inconsistent with the hypothesis of ULF modulation. A conclusion section ends our paper.

\section{Instrumentation}

\subsection{Magnetometer Arrays}

[9] The Canadian Array for Real-Time Investigations of Magnetic Activity (CARISMA; http://www.carisma.ca) is the continuation and expansion of the former CANOPUS magnetometer array deployed and operated by the University of Alberta [see Mann et al., 2008]. CARISMA has an upgraded cadence ( 8 samples/s), is expanded through the deployment of new stations, and uses new GPS-timed data loggers and a new data transmission system. At the moment, the array consists of both fluxgate and searchcoil magnetometers. In 2005, only fluxgate magnetometers operated. For this study, we hence use data only from the CARISMA fluxgate magnetometers with measurement resolution of $0.025 \mathrm{nT}$. The Solar-Terrestrial Environment Program (STEP) Polar Network (http://www-space.eps.s.u-tokyo.ac. $\mathrm{jp} / \sim$ hayashi) is an array of fluxgate and searchcoil magnetometers. The STEP searchcoil magnetometers provide measurements with cadence of 10 samples/s and resolution of $\sim 3 \mathrm{pT}$. We also use ground magnetic field data from the Scandinavian sector. Kiruna (Sweden) magnetometer station (http://www.irf.se) has a fluxgate magnetometer recording data at 10 samples/s. The Sodanskylä Geophysical Observatory in Finland (http://www.sgo.fi/Data/Pulsation/pulData. php) also runs an array of searchcoil magnetometers, where data are available at $40 \mathrm{samples} / \mathrm{s}$ time resolution. All magnetometer stations used in this work are listed in $L$ shell order in Table 1. 
Table 1. Details of Magnetometer Stations

\begin{tabular}{|c|c|c|c|c|c|c|c|c|}
\hline Station & Station Name & Type & $\begin{array}{c}\text { Sampling } \\
\text { Frequency } \\
(\mathrm{Hz})\end{array}$ & $\begin{array}{c}\text { Geocentric } \\
\text { Latitude }\end{array}$ & $\begin{array}{l}\text { Geocentric } \\
\text { Longitude }\end{array}$ & $\begin{array}{c}\text { Local } \\
\text { Magnetic } \\
\text { Midnight } \\
\text { (UT) }\end{array}$ & $L$ & Array/Chain \\
\hline 1 & Uzury (UZR) & Searchcoil & 10 & 53.32 & 107.74 & 1657 & 2.31 & STEP \\
\hline 2 & Lucky Lake (LCL) & Searchcoil & 8 & 51.00 & 252.90 & 0734 & 3.94 & STEP \\
\hline 3 & Pinawa (PINA) & Fluxgate & 8 & 50.20 & 263.96 & 0639 & 4.11 & CARISMA \\
\hline 4 & Parksite (PKS) & Searchcoil & 10 & 52.20 & 252.80 & 0736 & 4.23 & STEP \\
\hline 5 & Island Lake (ISLL) & Fluxgate & 8 & 53.86 & 265.34 & 0633 & 5.23 & CARISMA \\
\hline 6 & Rovaniemi (ROV) & Searchcoil & 40 & 66.78 & 25.94 & 2110 & 5.08 & Sodanskylä Observatory \\
\hline 7 & Sodanskylä (SOD) & Searchcoil & 40 & 67.42 & 26.39 & 2107 & 5.31 & Sodanskylä Observatory \\
\hline 8 & Fort McMurray (MCMU) & Fluxgate & 8 & 56.66 & 248.79 & 0800 & 5.41 & CARISMA \\
\hline 9 & Kiruna (KIR) & Fluxgate & 10 & 67.50 & 20.25 & 2127 & 5.45 & - \\
\hline 10 & Dawson (DAWS) & Fluxgate & 8 & 64.05 & 220.89 & 1027 & 6.10 & CARISMA \\
\hline 11 & Rabbit Lake (RABB) & Fluxgate & 8 & 58.22 & 256.32 & 0723 & 6.68 & CARISMA \\
\hline 12 & Fort Simpson (FSIM) & Fluxgate & 8 & 61.76 & 238.77 & 0858 & 6.84 & CARISMA \\
\hline
\end{tabular}

\subsection{Cluster}

[10] The four Cluster satellites [Escoubet et al., 2001] were launched into elliptical polar orbit with a period of $57 \mathrm{~h}$, perigee of $4 \mathrm{Re}$, and apogee of $19.6 \mathrm{Re}$. This makes it possible for Cluster to cross the ring current, the radiation belts, and the plasmapause on each perigee pass. All Cluster satellites carry identical instrumentation allowing for threedimensional observations of active processes in the Earth's magnetosphere. For this study, we use data from the Cluster fluxgate magnetometers (FGM) [see Balogh et al., 2001], electron drift instruments (EDI) [see Paschmann et al., 2001], electric field and wave instruments (EFW) [see Gustafsson et al., 2001], and waves of high frequency and sounder for probing of electron density for relaxation instruments (WHISPER) [see Décréau et al., 2001]. The Cluster FGM provides measurements of the magnetic field in the frequency range from DC to $10 \mathrm{~Hz}(32 \mathrm{~Hz}$ in burst mode) and measurement resolution of at least $0.1 \mathrm{nT}$. The Cluster EDI instrument allows for the measurements of the electric field once every $0.128 \mathrm{~s}$ (in normal mode) with accuracy of $0.1 \mathrm{mV} / \mathrm{m}$. EFW is important in this study as it also measures spacecraft floating potentials, which can represent a proxy for the ambient electron densities. WHISPER can also detect electron densities below $80 \mathrm{e} / \mathrm{cc}$.

\subsection{NOAA 17}

[11] NOAA 17 (The National Oceanic and Atmospheric Administration; http://www.ngdc.noaa.gov/stp/NOAA/noaa poes.html) is a polar-orbiting satellite. The NOAA 17 orbits are circular, with an altitude between 830 (morning orbit) and 870 (afternoon orbit) km, and are Sun synchronous. NOAA crosses the equator northbound around 22 MLT. NOAA 17 carries onboard a medium energy proton and electron detector (MEPED) that monitors intensities of charged particle radiation [Evans and Greer, 2000]. There are two identical proton telescopes: the $0^{\circ}$ detector, at high latitudes, monitoring particles in the atmospheric loss cone, and the $90^{\circ}$ detector, monitoring particles that are mirroring near the satellite. The detectors have $\pm 15^{\circ}$ FWHM (full with half maximum) field of view. The MEPED detector identifies protons within six energy ranges: $30-80,80-250,250-800$, $800-2500,2500-6900$, and above $6900 \mathrm{keV}$. For this work, we use data from the first three channels sampled at 0.5 samples/s.

\subsection{GOES 10 and 12}

[12] GOES 10 and 12 (The Geostationary Operational Environmental Satellites; http://www.ngdc.noaa.gov/stp/ GOES/goes.html) are positioned at geostationary orbits over the geographic equator and a few degrees off the geomagnetic equator. GOES-12 (or GOES-East) is located at $75^{\circ} \mathrm{W}$ geographic longitude, while GOES-10 (or GOES-West) is at $135^{\circ} \mathrm{W}$ geographic longitude. Both satellites have fluxgate magnetometers installed onboard that can detect magnetic field variations in the frequency range from DC to the $1 \mathrm{~Hz}$ Nyquist frequency [Singer et al., 1996].

\section{Observations}

[13] In this section, we present observations of EMIC waves and solar wind parameters on 25 September 2005.

\subsection{Geomagnetic Conditions}

[14] The EMIC wave event of 25 September 2005 followed 2 weeks of geomagnetic quiescence. During the day of 25 September, the Dst index (Figure 1a) had minor variations ranging from -12 to $7 \mathrm{nT}$. There is an $\mathrm{AE}$ enhancement of up to $500 \mathrm{nT}$ (Figure 1b) between approximately 1100 and 1400 UT associated with negative excursion in the GSM IMF Bz component (Figure 1d). After 1400 UT, the geomagnetic conditions were relatively undisturbed as indicated by the $\mathrm{Kp}$ index, which remained less than or equal to 1+ until 2200 UT (see Figure 1, top). Figures $1 \mathrm{c}-1 \mathrm{~g}$ show the IMF By and Bz in GSM coordinates and the solar wind velocity, density, and dynamic pressure, respectively, measured upstream by the ACE/Wind satellites, time-shifted to the Earth's magnetopause, and provided through the OMNI data base [see King and Papitashvili, 2004]. The solar wind density remained relatively high, especially between $\sim 0700$ and 1100 UT (Figure 1f), and the solar wind speed gradually increased from 300 to $400 \mathrm{~km} / \mathrm{s}$ (Figure 1e) so that the resultant dynamic pressure was enhanced between $\sim 0700$ and 1100 UT as well as after $\sim 1300$ UT. 

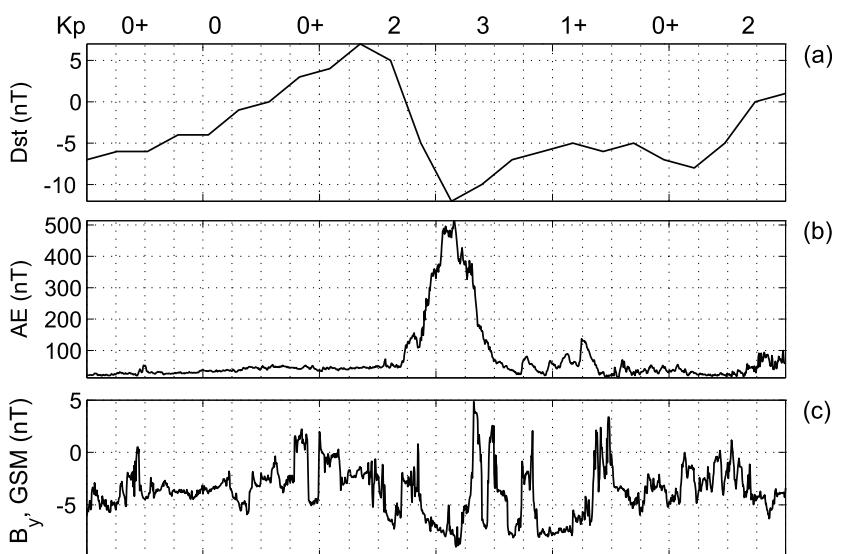

$E^{10}:$ :
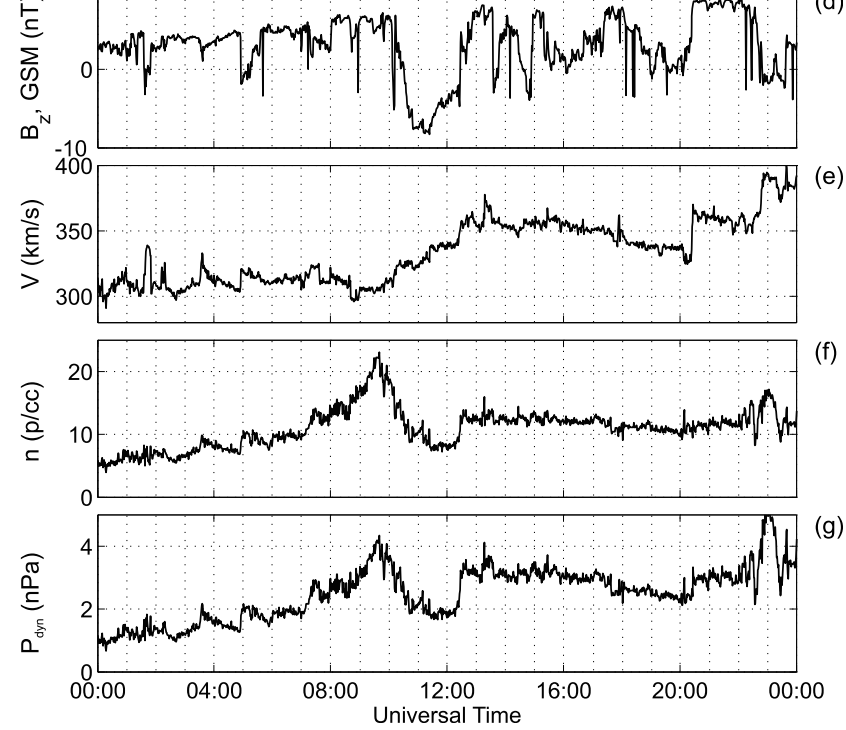

Figure 1. Geomagnetic indices and OMNI solar wind parameters on 25 September 2005: (top) Kp index, (a) Dst index, (b) AE index, (c) GSM IMF By, (d) GSM IMF Bz, (e) solar wind velocity, (f) solar wind ion density, (g) solar wind dynamic pressure. All OMNI data are time shifted to the dayside subsolar magnetopause.

\subsection{Conjugate EMIC Wave Observations by Cluster and Ground-Based Magnetometers}

[15] On 25 September, EMIC wave activity was detected throughout the day by multiple ground-based magnetometers in different MLT sectors. In response to the solar wind dynamic pressure enhancement between 0700 and 1100 UT (Figure 1g replotted in Figure 2a), EMIC waves appeared in the Scandinavian sector (morning MLT). Figure $2 \mathrm{~b}$ shows the spectrogram of the $\mathrm{X}$ component (geographic north-south) of the magnetic field measured at the Kiruna magnetometer station (KIR; $L=5.45$ ). Consistent with the observations by Usanova et al. [2008], the EMIC wave power ceases between $\sim 1100$ and 1230 UT when the solar wind dynamic pressure decreases, and EMIC wave power returns later when the second burst of enhanced solar wind pressure causes EMIC wave power to start growing again. A similar situation where two EMIC wave bursts appear during the strongest solar wind dynamic pressure was also observed by the Sodanskylä observatory magnetometer array (not shown) in the Finnish sector between $\sim 0700-1100$ and $\sim 1300-1600$ UT. The most intense EMIC waves were detected by the magnetometers at Rovaniemi (ROV; $L=5.08$ ) and Sodanskylä (SOD; $L=$ 5.31). The quicklook spectrograms from the Finnish sector are available through the Sodanskylä Geophysical Observatory website (http://www.sgo.fi/Data/Pulsation/pulData. php).

[16] During the second interval of enhanced solar wind dynamic pressure, Canadian magnetometers (shown on map in Figure 3) rotated into the morning MLT sector. At around 1300 UT IPDP pulsations, probably a remnant of the preceding $\mathrm{AE}$ enhancement or a response to the enhanced dynamic pressure, appeared. Further, starting at 1500 UT and lasting for $3.5 \mathrm{~h}$, structured Pc1 activity in the frequency range from 0.65 to $0.75 \mathrm{~Hz}$ (close to the frequency observed by Scandinavian magnetometers) was detected (Figure $2 \mathrm{~d}$ ). For this interval, we also have magnetic field data from the GOES 10 and 12 satellites located over Canada. The structured Pc1 pulsations appeared on the ground when associated magnetospheric compression, observed as an
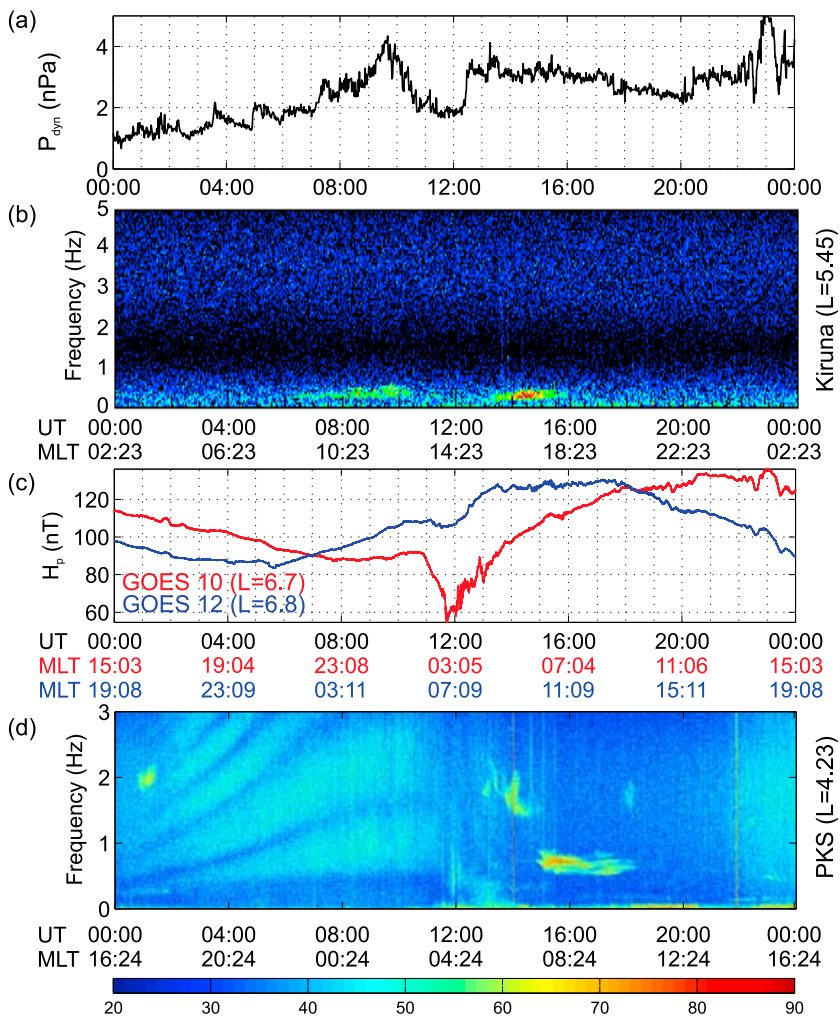

Figure 2. (a) Solar wind dynamic pressure $P_{\text {dyn }}$ (also shown in Figure 1g). (b) Fourier spectrogram of the $\mathrm{X}$ component of magnetic (geomagnetic north-south) from the Kiruna station. (c) Magnitude of the Hp component of the magnetic field observed at GOES 10 (red line) and GOES 12 (blue line). (d) Fourier spectrogram of the D component (geomagnetic east-west) of the magnetic field from the Parksite station on 25 September 2005. The spectrogram also shows signatures of the ionospheric Alfvén resonator between 0000 and 1100 UT [see Parent et al., 2007]. 

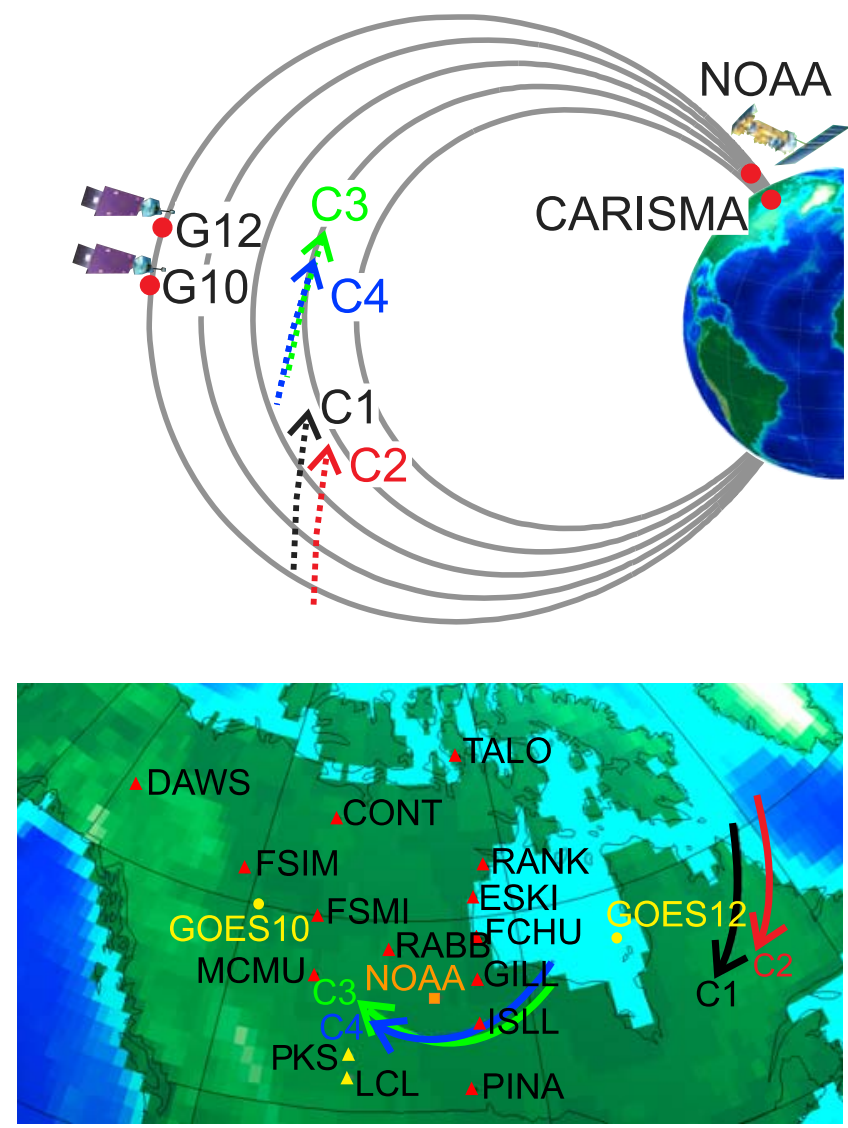

Figure 3. (top) Schematic showing the observation points: GOES satellites at the geosynchronous orbit, Cluster 3 and Cluster 4 in the equatorial plane at 1730-1830 UT, Cluster 1 and Cluster 2 at $\sim 20^{\circ}$ off the equator between 1430 and 1500 UT, NOAA 17 above Canada at 1751 UT moving northward, CARISMA on the ground. (bottom) Locations of the selected CARISMA and STEP magnetometer stations and the magnetic footprints of Cluster, GOES, and NOAA 17 mapped to the ground with the T96 model (Cluster 1 and Cluster 2 between 1430 and 1500 UT, Cluster 3 and Cluster 4 between 1730 and 1830 UT, NOAA 17 at 1751 UT). The red and yellow triangles indicate sites with fluxgate and searchcoil magnetometers, respectively.

increase in the magnitude of the magnetic field at GOES 12, reached its maximum as seen in the Hp (parallel to the Earth's spin axis and sensor most closely aligned with the magnetic field) magnetic field component (blue line in Figure 2c). Later, an enhanced Hp was also seen at GOES 10 as it entered the morning MLT sector (red line in Figure 2c). Overall, the magnitude of the Hp component recorded by the GOES satellites on the dayside was by $24 \mathrm{nT}$ larger than during the days of more usual solar wind dynamic pressure.
[17] Structured Pc1 pulsations were also registered by other Canadian magnetometer stations shown on the map in Figure 3. Figures $4 \mathrm{a}-4 \mathrm{~g}$ show the Fourier spectrograms of the D component (geomagnetic east-west) of magnetic field at Lucky Lake (LCL; $L=3.94$ ), Parksite (PKS; $L=4.23$ ), Island Lake (ISLL; $L=5.23$ ), Fort McMurray (MCMU; $L=$ 5.41), Dawson (DAWS; $L=6.10$ ), Rabbit Lake (RABB; $L=$ 6.68), and Fort Simpson (FSIM; $L=6.84$ ) from 1400 to 1900 UT, respectively. Similar EMIC wave packet structures are also seen in the H component (geomagnetic north-south). Because of the propagation effect in the Earth-ionosphere waveguide, the EMIC waves are likely to be seen far from the magnetic footprint of the source region. However, EMIC wave power is expected to be attenuated over the propagation path. Comparing the wave intensities at multiple magnetometer stations, it is therefore possible to establish the probable location of the ionospheric projection of the source region as corresponding to the region of maximum EMIC wave power seen on the ground. The most intense waves observed by the fluxgate magnetometers shown in Figure 3 (bottom) were localized around $L \sim 5$, as indicated by the spectrograms in Figures $4 \mathrm{c}$ and $4 \mathrm{~d}$. The fluxgate magnetometers located at higher $L$ values observed less intense waves (see Figures $4 \mathrm{e}-4 \mathrm{~g}$ ), and the one located at Pinawa (PINA; $L=4.11$ ) did not register any EMIC activity at all (not shown). However, the two STEP searchcoil magnetometers at Parksite (PKS; $L=4.23$ ) and Lucky Lake (LCL; $L=3.94$ ) did register Pc1 pulsations. This can be explained by the fact that the searchcoil magnetometers are more sensitive to the field variations in this frequency range than the fluxgate magnetometers.

[18] It should be also noted that during the period of $\mathrm{AE}$ enhancement (1100-1400 UT) EMIC waves were registered by the Uzury magnetometer (UZR; $L=2.31$ ) between $\sim 19$ and 21 MLT. The intensity of the pulsations at Uzury was relatively low, most probably because the footprint of the source region was located at a higher $L$ shell. These duskside observations point to a different (rather than enhanced $\left.P_{\text {dyn }}\right)$ source mechanism for EMIC wave generation at Uzury consistent with the "more traditional" hypothesis that EMIC waves are excited in the duskside magnetosphere due to enhanced magnetospheric convection and/or ion injection.

[19] During the 25 September, the four Cluster spacecraft were located in the dayside magnetosphere, and three of them detected EMIC waves. Figure 3 shows the locations of the Cluster satellites in the magnetosphere along with their magnetic footprints mapped to the ground with the T96 model [see Tsyganenko, 1996]. First, between 1450 and 1500 UT EMIC activity at $0.3-0.5 \mathrm{~Hz}$ appeared at Cluster 1 localized from $L=5.7$ to $L=6.4$ at approximately $20^{\circ}$ below the magnetic equator (Figure 5a) in a high-density region (based on the spacecraft potential measurements) just inside the plasmapause, consistent with the observations by Usanova et al. [2008]. It should also be noted that the magnetic footprints of Cluster 1 were located at more than $3 \mathrm{~h}$ to the east from the ground magnetometer stations in the

Figure 4. Fourier spectrograms of the D component (geomagnetic east-west) of magnetic field from selected CARISMA and STEP stations (see text) between 1400 and 1900 UT. Note that the top two panels show data from searchcoil magnetometers. As searchcoil magnetometers are more sensitive to magnetic field fluctuations in this frequency range, the relative wave spectral magnitude between the sets of data from the two types of instrument should not be compared. 
(a)

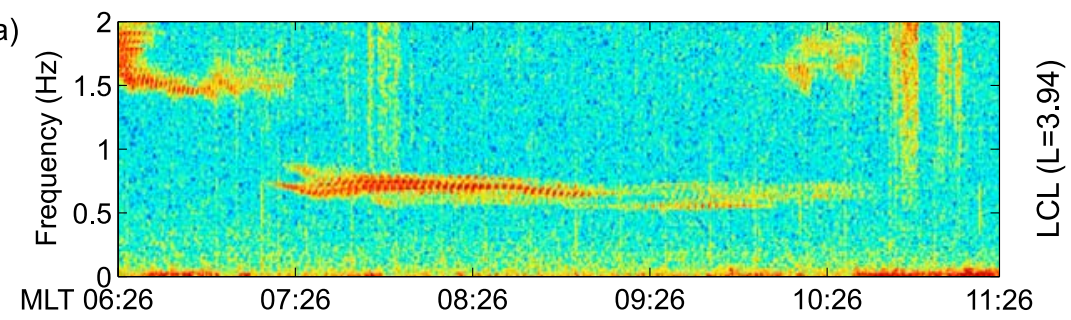

(b)

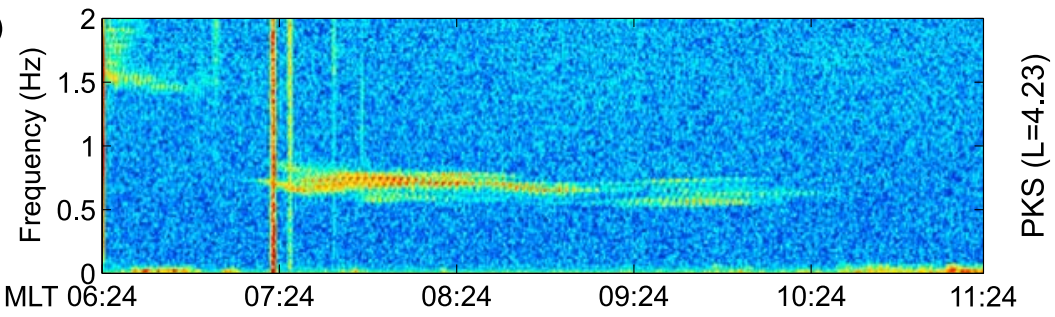

(c)

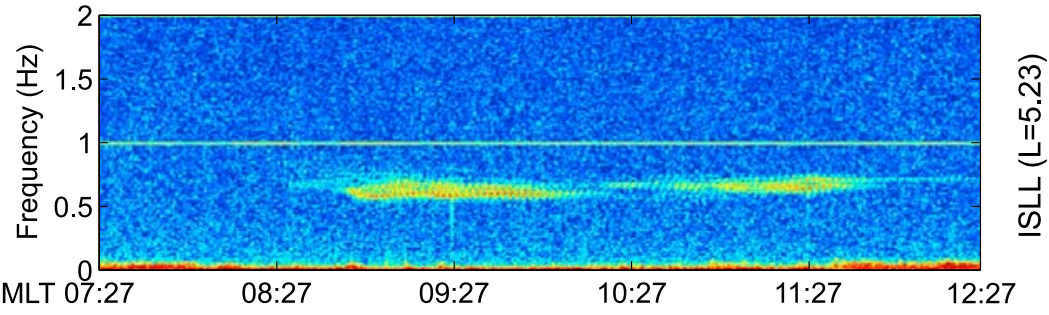

(d)

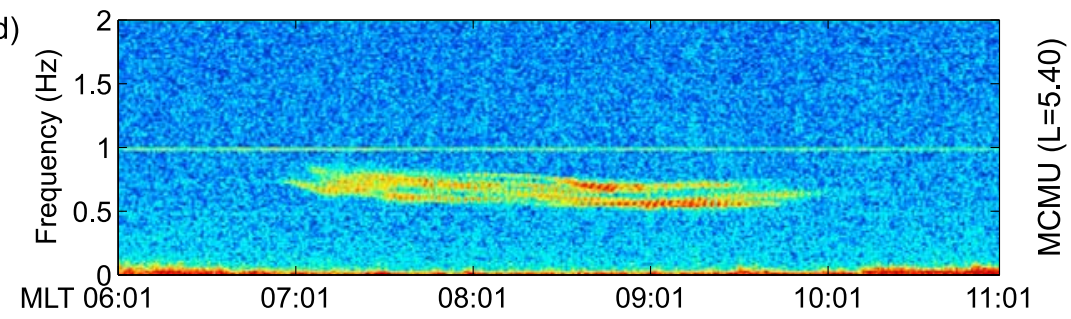

(e)

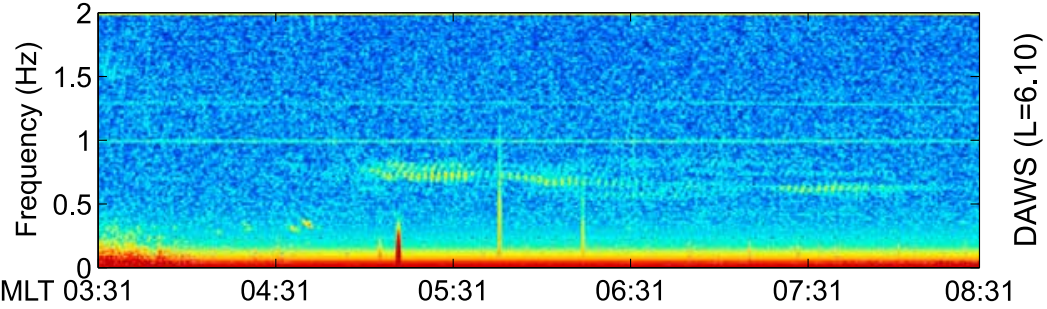

(f)

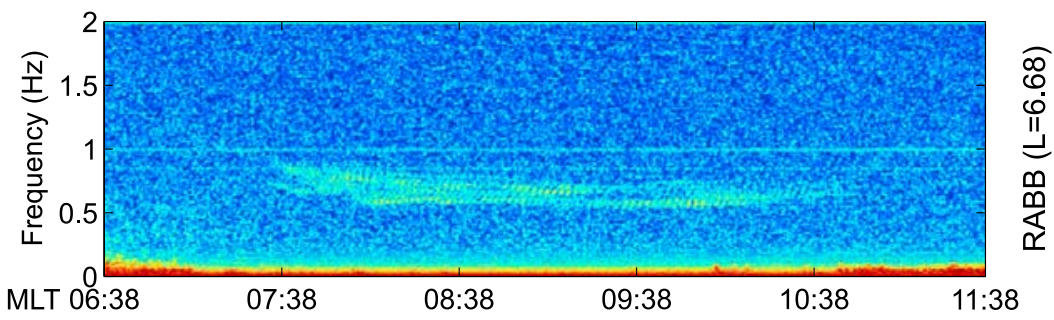

(g)

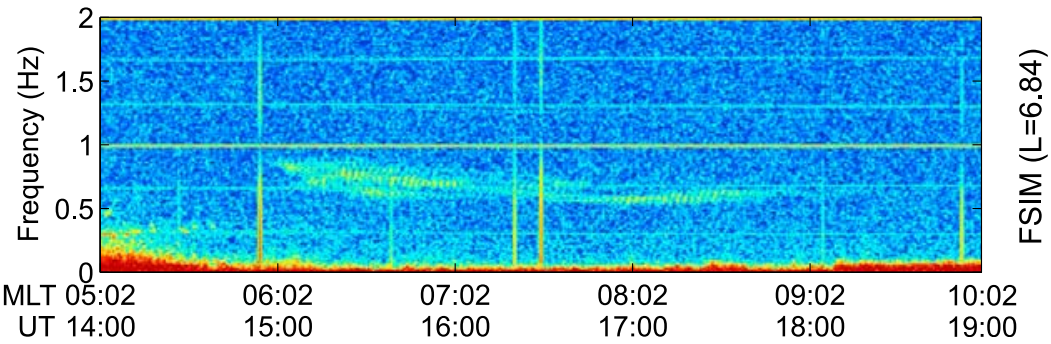

Figure 4 

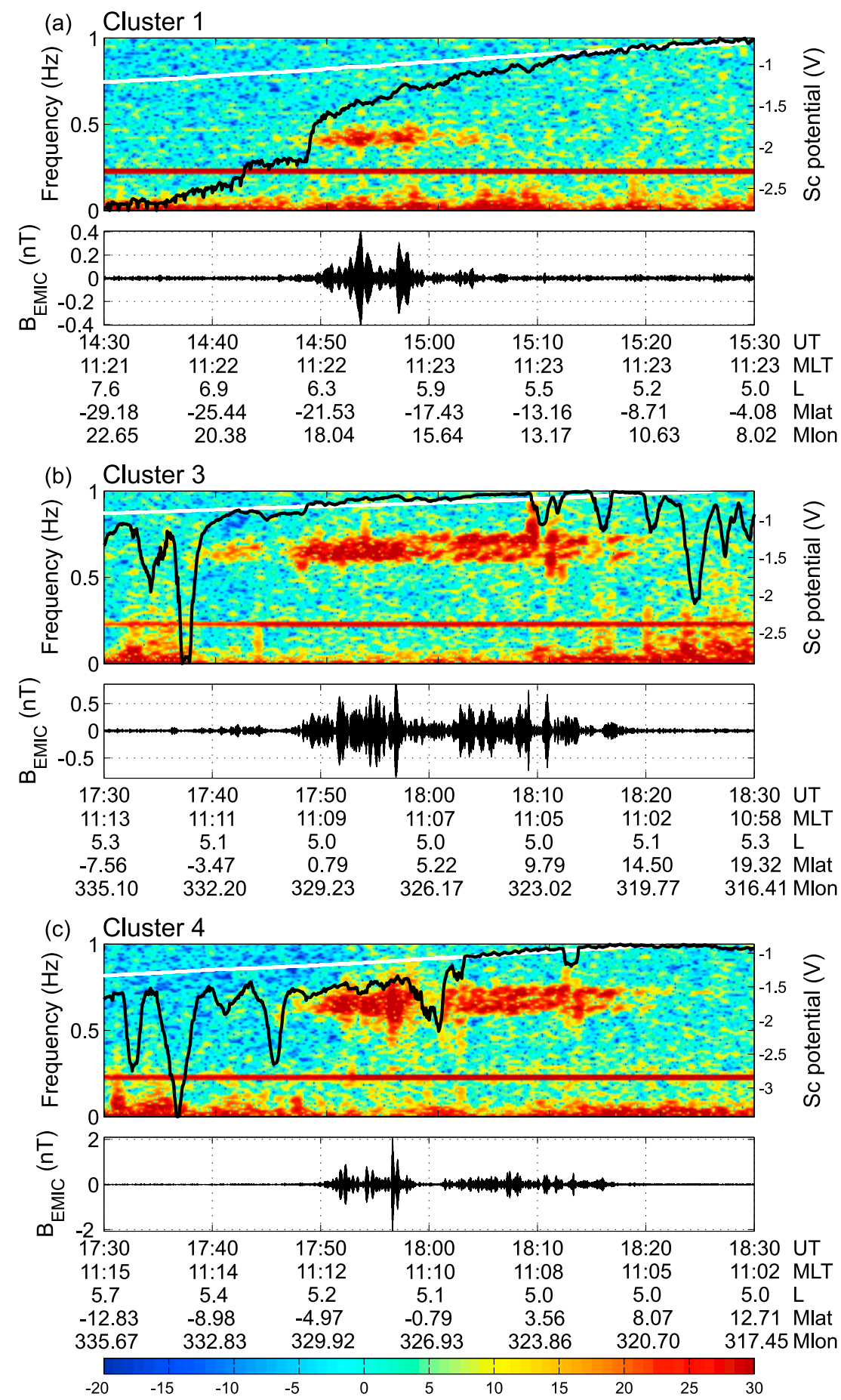

Figure 5. (top) Fourier spectrogram and (bottom) waveforms of the perpendicular (azimuthal) magnetic field component in field-aligned coordinates for $1 \mathrm{~h}$ windows at Cluster 1, Cluster 3, and Cluster 4 in Figures 5a, 5b, and 5c, respectively. Over-plotted in each panel are the spacecraft potential (black line) and the local helium gyrofrequency (white line). See text for details. The bright red line in each spectrogram corresponds to the Cluster spin period (4 s).

Canadian sector (black arrow on the map in Figure 3), and the waves observed at Cluster 1 between $\sim 1450$ and 1505 UT were not seen on the ground by the magnetometers used in this work. Later, EMIC waves were detected by Cluster 3 and Cluster 4 in the equatorial plane during their perigee passes between $\sim 1745$ and 1815 UT. At this time, Cluster 3 and Cluster 4 were in a very good magnetic conjunction with the Island Lake magnetometer station (footprints of the trajectories are shown by the blue and green arrows on the map in Figure 3) and observed EMIC waves in the frequency band between 0.65 and $0.75 \mathrm{~Hz}$ matching the one on the ground. 

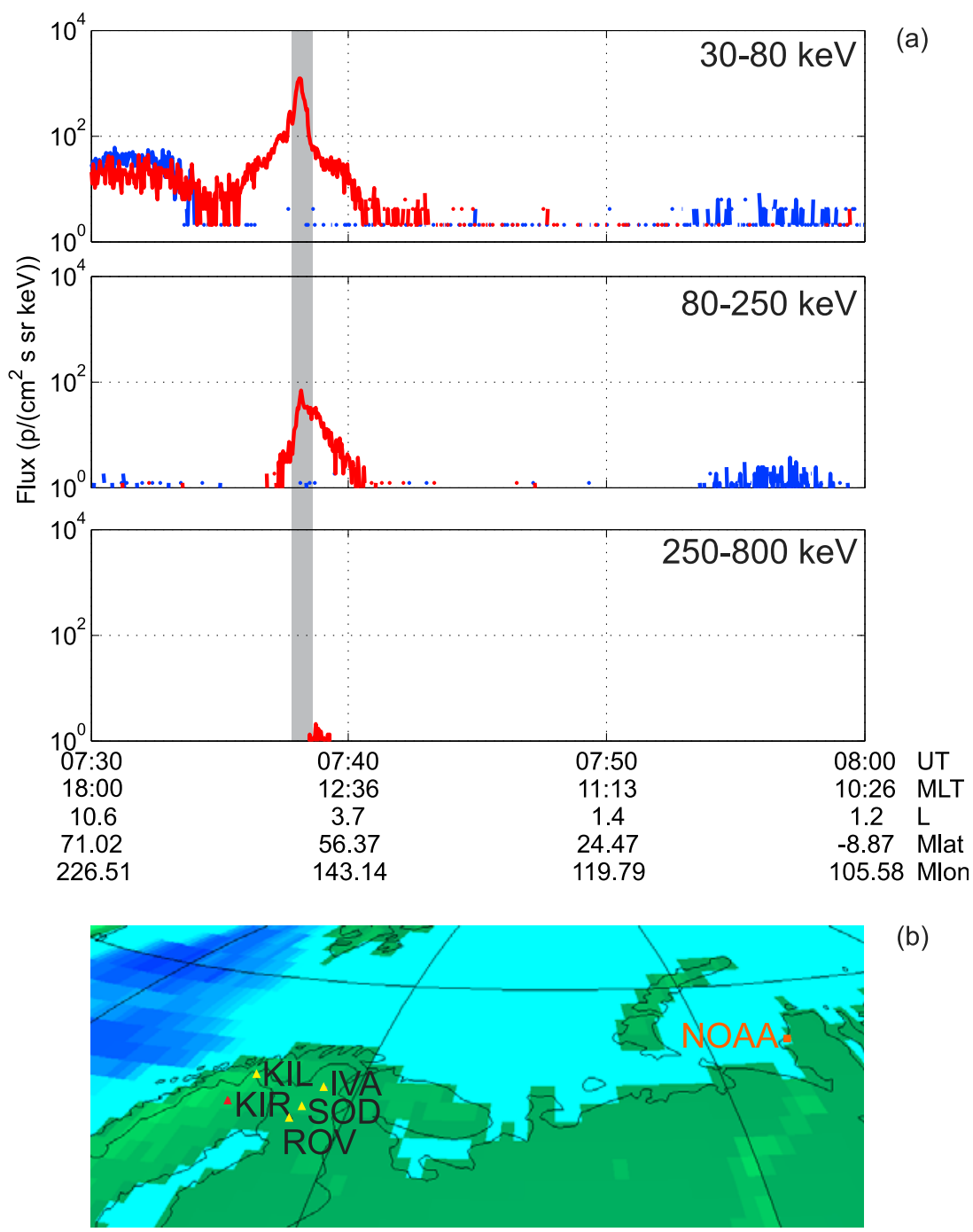

(b)

Figure 6. (a) Proton differential flux in three energy channels: (top) $30-80 \mathrm{keV}$, (middle) $80-250 \mathrm{keV}$, (bottom) $250-800 \mathrm{keV}$ registered by NOAA 17 . Locally mirroring and precipitating particle fluxes are shown in red and blue color, respectively. At 0738 UT (shadowed bar), the satellite was $\sim 40^{\circ}$ east of the Scandinavian sector. (b) Location of NOAA 17 magnetically mapped to the ground with T96 with respect to the ground-based magnetometers.

[20] Figure 5 shows the spectrograms and waveforms of the perpendicular (azimuthal) magnetic field component. The magnetic field data have been transformed from the GSM into local field-aligned coordinates using the procedure described by Rae et al. [2005]. In this coordinate system, the azimuthal direction is perpendicular to both the direction of the background magnetic field and the radial direction, which lies in the plane containing the vector from the center of the Earth to the satellite.

[21] In a multicomponent magnetospheric plasma, there are forbidden band gaps for EMIC wave generation and propagation, generally, around heavy ion gyrofrequencies that split the wave spectrum into multiple branches. It can be seen that the observed EMIC wave emissions lie on the "helium" branch (with frequency below the local helium gyrofrequency, shown in each spectrogram by the white line). Typically, there is a gap between a branch cutoff frequency and the corresponding heavy ion gyrofrequency.
The width of this gap depends on the heavy ion concentration, temperature, and anisotropy [see, e.g., Gendrin et al., 1984]. The polarization of the waves at Cluster 1, Cluster 3, and Cluster 4 is left-handed (not shown here), consistent with the direction of ion rotation around the magnetic field, and with expectations from the theory of EMIC wave generation if Cluster is observing the EMIC waves close to the source region. The black lines show the EFW spacecraft floating potentials, indicators of the background electron density, [e.g., Pedersen et al., 2001]. More negative values (more positive values) of floating potentials correspond to a lower (higher) electron density of the surrounding plasma. We have estimated the related electron densities using the WHISPER instrument data. The interesting feature is that the EMIC waves appeared to be confined within the region of high electron density $(>70 \mathrm{e} / \mathrm{cc})$ and follow nicely the density structures observed by Cluster 3 and Cluster 4 on their inbound and outbound passes through 


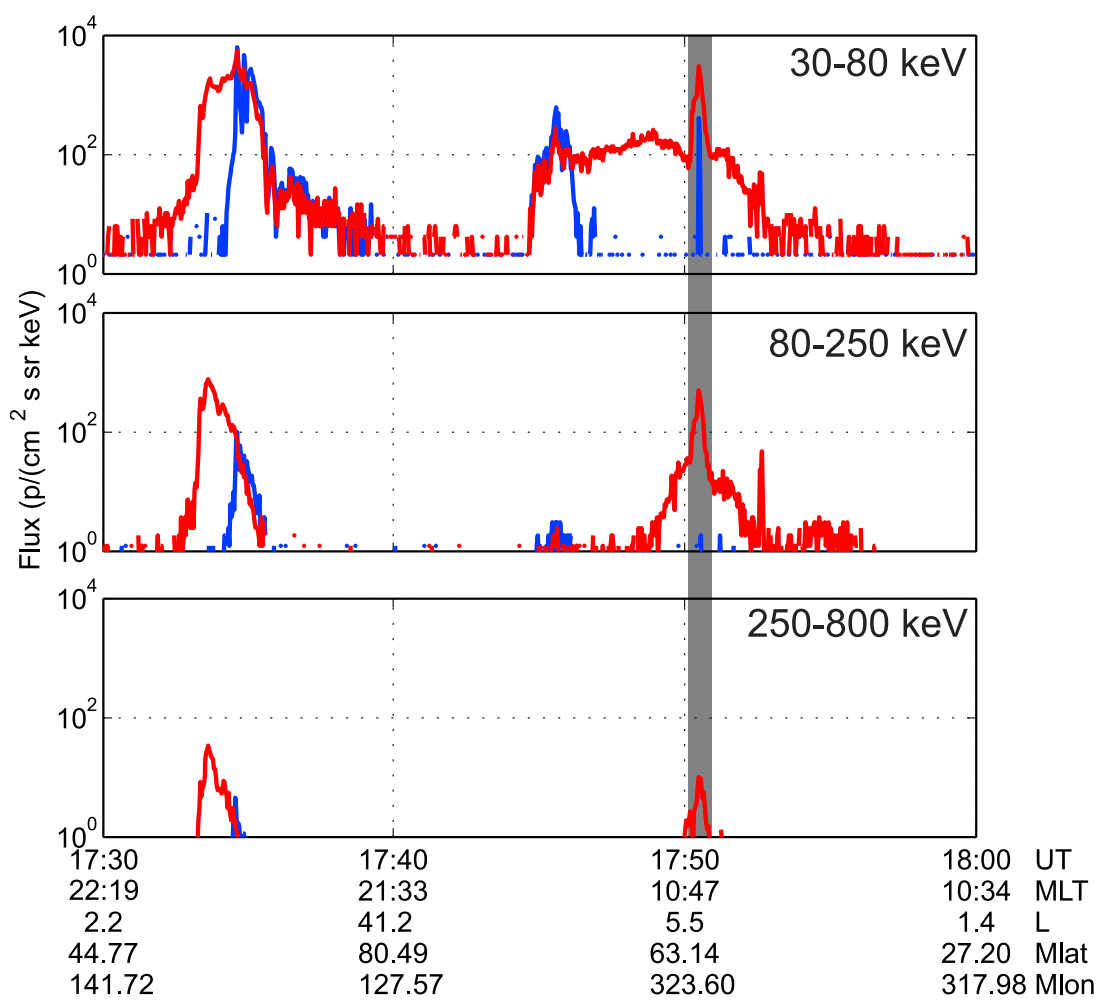

Figure 7. Similar to Figure 6a. Proton differential flux in three energy channels: (top) $30-80 \mathrm{keV}$, (middle) $80-250 \mathrm{keV}$, (bottom) $250-800 \mathrm{keV}$ registered by NOAA 17 . Locally mirroring and precipitating particle fluxes are shown in red and blue color, respectively. At 1751 UT (shadowed bar), the satellite was above Canada, in good conjunction with Cluster 3, Cluster 4, and CARISMA (see Figure 3).

the plasmapause. Clearly, the cessation of EMIC wave activity seen on Cluster 3 at 1810 UT and on Cluster 4 at 1800 UT is associated with the density drops as monitored by spacecraft potential. Appearance of the EMIC waves in regions of higher plasma densities is consistent with the EMIC wave theory predictions, as a larger convective wave growth is expected here [e.g., Kozyra et al., 1984].

\subsection{EMIC-Related LPEP}

[22] During the day of 25 September, the LEO orbit NOAA satellites registered enhanced precipitation of energetic protons at midlatitudes, collocated in space and time with EMIC activity observed on the ground. We present two examples of such precipitation at different universal times, but both in the morning MLT sectors. At 0738 UT, the NOAA 17 spacecraft registered a localized enhancement of precipitating protons with energies of $>30 \mathrm{keV}$ (shaded bar in Figure 6a) above the north of Russia, at $\sim 40^{\circ}$ east of the Scandinavian sector. The position of NOAA 17 at 0738 UT magnetically mapped to the ground is shown by the orange square in Figure 6b. The blue trace in Figure 6a shows the flux of precipitating protons (observed by the $0^{\circ}$ detector) and the red trace shows the flux of locally mirroring protons (observed by the $90^{\circ}$ detector) seen by MEPED. The three panels in Figure 6a show data from different energy channels, between $30-80 \mathrm{keV}, 80-250 \mathrm{keV}$, and $250-800 \mathrm{keV}$, respectively. Following the classification of Yahnin and Yahnina [2007], we identify this proton event as LPEP of type 1 , i.e., characterized by localization in the morning MLT sector during quiet geomagnetic conditions, without the presence of a precipitating energetic electron population, and in conjunction with structured Pc1 pulsations observed on the ground. These authors note that generally during type 1 events, the precipitating flux is relatively small compared to the trapped flux, which points to weak pitch angle diffusion of particles with pitch angles close to the loss cone.

[23] Figure 6a also shows broader precipitation, which comes from the so-called "isotropic precipitation zone." This zone is magnetically conjugated to the midtail, where field lines are strongly stretched, and the ion gyroradius becomes comparable to the radius of curvature of the local magnetic field. Precipitation in this zone is nonadiabatic and is of different origin than the one considered in this work.

[24] At 1751 UT, simultaneously with the EMIC activity seen on Cluster, the NOAA 17 spacecraft registered a localized enhancement of precipitating protons with energies of $>30 \mathrm{keV}$ (shaded bar in Figure 7) in LEO orbit over Canada, closely conjugated to both the Cluster 3 and Cluster 4 satellites and CARISMA. The position of NOAA 17 at 1751 UT magnetically mapped to the ground is shown by the orange square in Figure 3. Similar to Figure 6a, the blue trace denotes the flux of precipitating protons and the red trace shows the flux of locally mirroring protons registered by MEPED. In this case, we can see that the precipitating flux in the first channel (Figure 7, top) is almost as intense as the mirroring flux, which serves as an indication of strong pitch angle scattering for ions with energies between 30 and $80 \mathrm{keV}$, while for the higher energies pitch angle diffusion is weaker. The increase in the pitch angle diffusion rate may be associated with the preceding injection of ions manifested 

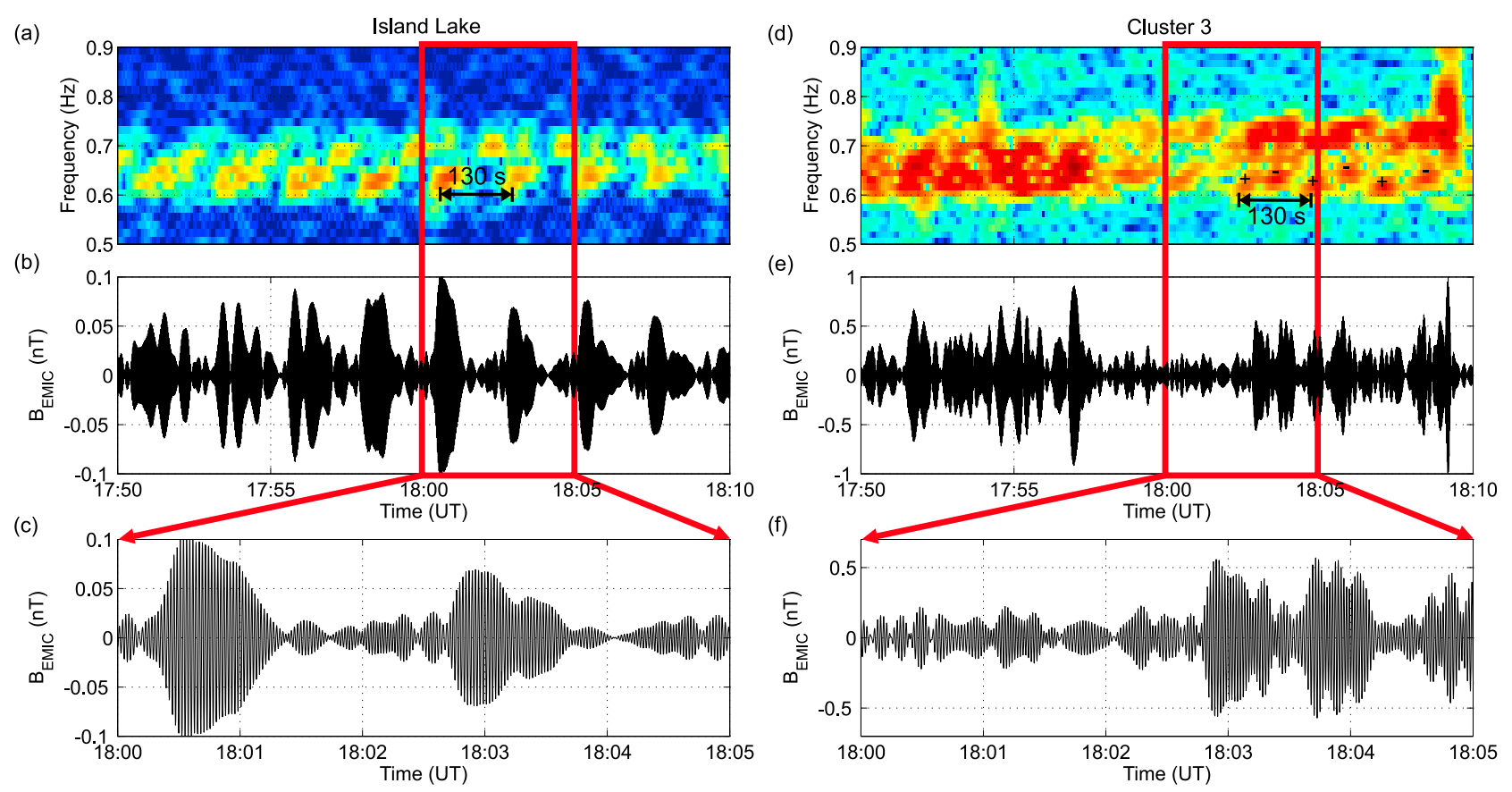

Figure 8. Fourier spectrograms and waveforms of (left) the D component at ISLL and (right) azimuthal magnetic field component at Cluster 3 zoomed in between 1750 and 1810 UT and between 1800 and 1805 UT to show the EMIC wave packet details.

by the enhancement in the AE index. Our observations suggest that strong energy-dependent ion loss may occur during periods of geomagnetic quiescence, which are characterized by EMIC waves excited at midlatitudes just inside the plasmapause by strong compression of the magnetosphere due to enhancement in solar wind dynamic pressure.

\subsection{EMIC Wave Modulation by Lower-Frequency ULF Waves}

[25] Simultaneous CARISMA-Cluster observations also provide the opportunity to test the bouncing wave packet model and the theory of EMIC wave growth modulation by the lower frequency ULF waves. At multiple CARISMA and STEP magnetometer stations, the EMIC waves appear to be structured with repetition period of 130-140 s (see Figure 8) across a relatively wide range of $L$ shells. Simultaneously with the waves on the ground, Cluster 3 and Cluster 4 registered EMIC waves with the same carrier frequency in the equatorial region magnetically conjugated to CARISMA. The equatorial location of the Cluster 3 and Cluster 4 observations and the left-handed EMIC wave polarization lead us to conclude that Cluster flew through the EMIC wave source region.

[26] To illustrate details of the EMIC wave packet structure, we have selected a 20 min interval that is shown in Figure 8 . Figure 8 (left and right) shows Fourier spectrograms and waveforms of the D component at ISLL and azimuthal magnetic field component in FAC at Cluster 3, respectively, zoomed in between 1750 and 1810 UT and between 1800 and 1805 UT. On the ground, the EMIC wave packets repeat about every $130 \mathrm{~s}$, and this repetition period appears in spectrograms as stripes or blobs. The individual wave packets on Cluster 3 are more diffuse, and it is harder to distinguish them. However, the wave packet structure is still seen after 1800 UT in the spectrogram at frequencies below $0.65 \mathrm{~Hz}$, which repeat every $65 \mathrm{~s}$ on Cluster 3 opposed to the $130 \mathrm{~s}$ on the ground. This observation suggest that the wave packets propagate bidirectionally in the source region, which we marked in the spectrogram in Figure $8 \mathrm{~d}$ by the "+" and "-" signs, consistent with observations by Loto'aniu et al. [2005], while only every second wave packet is seen on the ground in the Northern Hemisphere. Following Loto'aniu et al. [2005], we computed the EMIC Poynting flux using the FGM and EFW instruments on Cluster. However, because of the noise in the EFW data, the Poynting flux analysis does not show clear results. Nevertheless, there is some evidence of bidirectional propagation of the EMIC wave packets.

[27] Also note that the EMIC wave spectrum after 1800 UT bifurcates into two closely spaced bands, which happens both in space and on the ground. Such multiple wave bands are often observed on the ground and were previously explained by EMIC wave generation at different source regions in the magnetosphere, each frequency band corresponding to the local ion gyrofrequency and their consequent ionospheric ducted propagation to the ground magnetometer station [see, e.g., Yahnin et al., 2004]. Since in our case the spectrum splitting occurs at the spacecraft, this cannot be attributed to multiple-source locations. Analysis of the wave properties in the generation region, potentially via self-consistent simulations, is warranted.

[28] To test the ULF wave modulation hypothesis, we used the EDI electric and the FGM magnetic field measurements from Cluster. Prior to the analysis, Cluster electric and magnetic field data were transformed from GSM to the field-aligned coordinate system [see Rae et al., 2005] and FFT-transformed to the frequency domain. The time series of the EDI electric field are shown in Figure 9 (top) 
Cluster 1 EDI
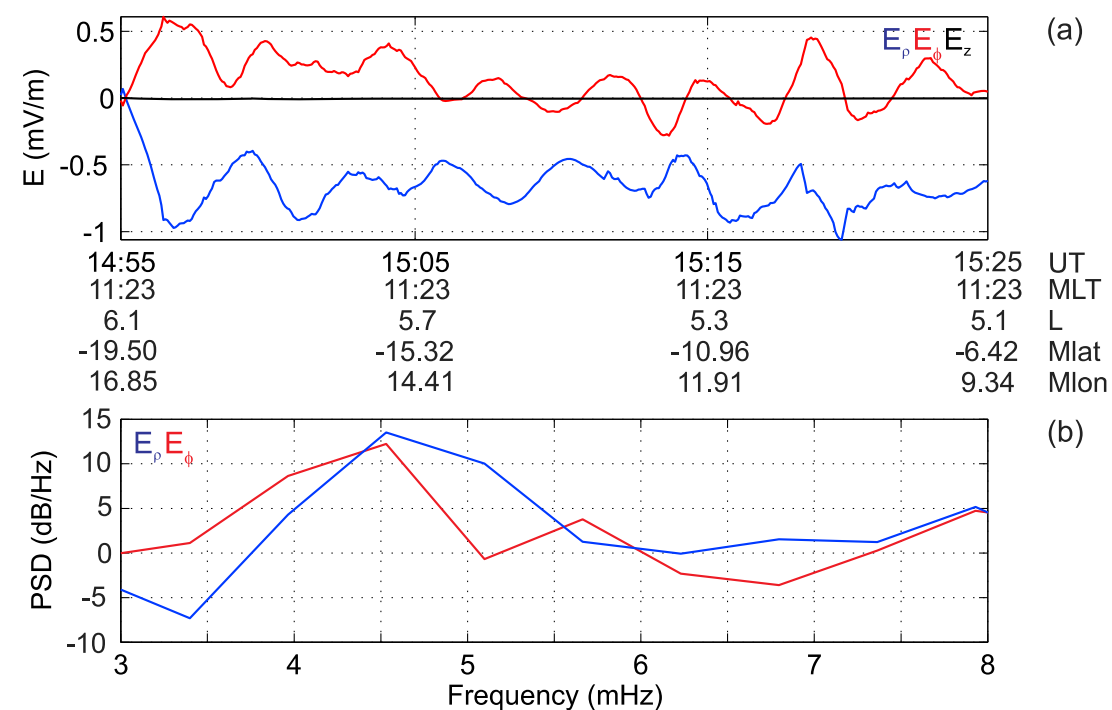

Cluster 3 EDI
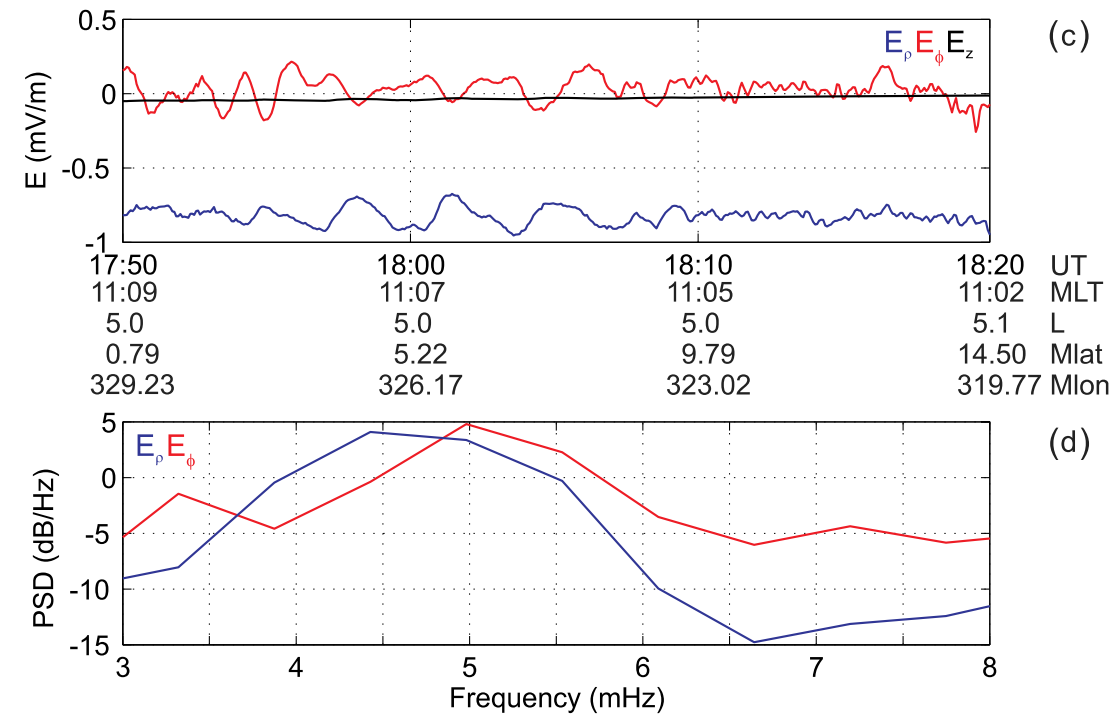

(d)

Figure 9. (a) EDI electric field time series and (b) power spectral density between 1455 and 1525 UT registered on Cluster 1. (c) EDI electric field time series and (d) power spectral density between 1750 and 1820 UT registered on Cluster 3.

and the power spectral density is in Figure 9 (bottom) for Cluster 1 and Cluster 3, respectively.

[29] According to the EMIC wave modulation theory, the lower-frequency ULF waves with average period of 130 $140 \mathrm{~s}(7.1-7.7 \mathrm{mHz})$ should be observed in situ in the EMIC wave source region at the equator. However, these ultra low frequency waves are not seen in the magnetic field data, neither in the time series nor in the spectrum (not shown). The Cluster 3 EDI electric field measurements do show the presence of ULF electric field (see Figure 9) with period of $192 \pm 11 \mathrm{~s}(5.2 \pm 0.3 \mathrm{mHz})$. Similar long-period ULF waves are found earlier in the Cluster 1 EDI data. However, this period is considerably longer than the observed EMIC wave packet repetition period on the ground. Magnetic field data obtained from CARISMA magnetometers do not show any presence of ULF waves with periods around 130-140 s, either. To examine the feasibility of having local ULF waves with periods equal to the EMIC modulation period on the ground, we applied cross-phase analysis [e.g., Waters et al., 1996] to data from pairs of CARISMA magnetometers along the $\sim 330^{\circ}$ magnetic meridian. This technique assumes that magnetic field lines sustain standing Alfvén waves with frequencies depending on the field line length and Alfvén speed along it. In order to extract field line resonance frequency values, amplitude and phase spectra from pairs of latitudinally separated ground-based magnetometers are compared to look for features of resonance. A peak of phase difference (cross phase) occurs at the field line resonance frequency of the field line with its footprint at the midpoint between the two magnetometers. Figure 10a shows the cross-phase spectra from the Island Lake and Gillam magnetometers (the closest pair to the Cluster 3 and Cluster 4 footprints). Cross-phase FFT windows were $30 \mathrm{~min}$ long, providing a frequency resolution of $0.5 \mathrm{mHz}$. There are 


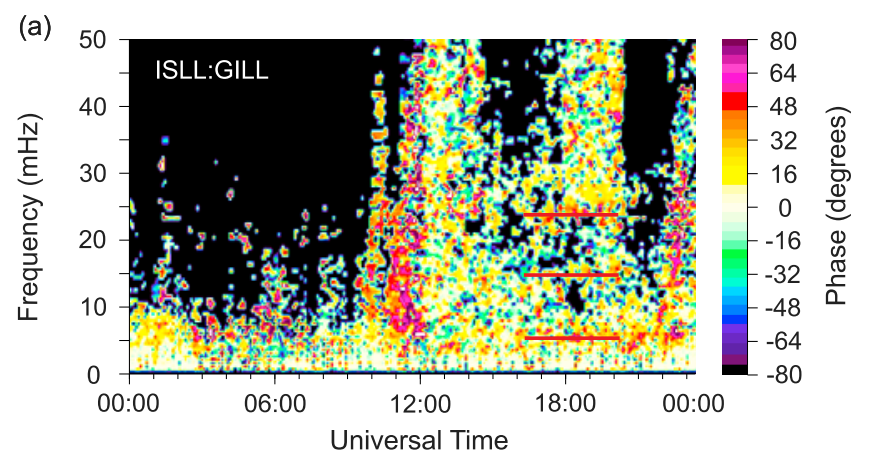

(b)

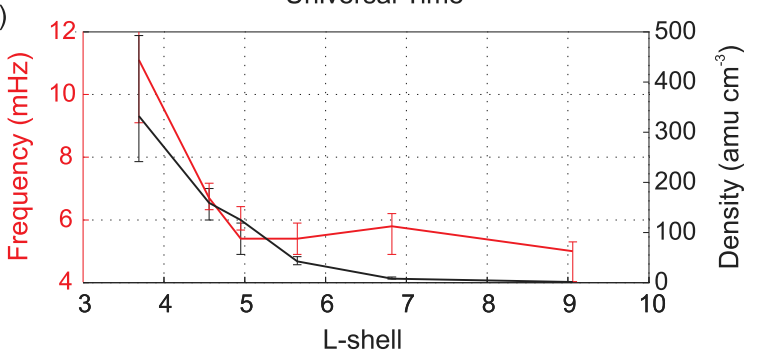

Figure 10. (a) Cross-phase spectra of local resonance modes at the midpoint between the Island Lake $(L=5.23)$ and Gillam $(L=6.10)$ stations. (b) The fundamental field line resonance frequency (blue line) and equatorial mass density (black line) derived from ground-based cross phase as a function of $L$.

three resonance modes seen in the spectra: the fundamental mode at $5.4 \pm 0.5 \mathrm{mHz}(185 \pm 17 \mathrm{~s})$ and the second and the third harmonics at $14.5 \pm 0.5 \mathrm{mHz}(69 \pm 2 \mathrm{~s})$ and $22.5 \pm$ $0.5 \mathrm{mHz}(44 \pm 1 \mathrm{~s})$, respectively (indicated in Figure 10a by horizontal red lines). The good agreement between the period of field line fundamental mode and the period of electric field oscillations on Cluster and the absence of magnetic field oscillations on Cluster is consistent with this being an observation of the fundamental field line standing Alfvén wave having a node at the equator in magnetic field and an antinode in the electric field [see, e.g., Southwood and Kivelson, 1981] (the absence of magnetic field oscillations at the resonance frequency on the ground might be due to the fact that this is a small spatial scale wave, strongly attenuated between the ionosphere and the ground [see, Wright and Yeoman, 1999]). However, our observations do not agree with the theory that EMIC wave growth modulation by lower-frequency ULF magnetic pulsations can explain the form of structured Pcl pulsations, since waves with period matching the EMIC repetition period on the ground were not found in the Cluster data.

[30] Generally, high harmonic $(n \geq 2)$ field line resonance eigenperiods can be used to calculate the Alfvénic travel time there and back along the field line [see Schulz, 1996]. Assuming that EMIC waves propagate in the magnetosphere approximately at the Alfvén speed, we have estimated the EMIC wave travel time there and back along the source field line to be $\tau=n T_{n}=3 \times 44=132 \mathrm{~s}$. This is close to the repetition period of the wave packets seen on the ground. This good agreement between the estimated wave travel time along the magnetic field line and the EMIC wave repetition period on the ground, as well as the observation of a double-hop $65 \mathrm{~s}$ wave repetition period (although, for a short interval of time) on Cluster, could be possibly explained by the wave packet bouncing between hemispheres.

[31] The cross-phase analysis was also used to relate the observed electron density structures inferred from the WHISPER and EFW instruments at Cluster to a potential plasmapause location obtained from ground-based magnetometer measurements. Figure $10 \mathrm{~b}$ shows the fundamental field-line resonance frequency (blue line) and equatorial mass density (black line) as functions of $L$ derived from the cross-phase analysis applied along the "Churchill line" at $330^{\circ}$ magnetic meridian. Plasma mass densities were derived from the field line resonance frequencies, assuming a dipole field geometry and radial density distribution along field lines $\sim r^{-1}$ [see, e.g., Dent et al., 2003]. The plasma mass density profile shows consistency with WHISPER electron densities observed by Cluster 3 and Cluster 4.

\section{Conclusions}

[32] In this paper, we have analyzed EMIC waves generated during solar wind-driven magnetospheric compressions. Using conjugate observations from the Cluster satellites and CARISMA and other ground-based magnetometers, we show that EMIC waves were excited in a high-density region just inside the plasmapause. Importantly, we were also able to analyze the effect of these EMIC waves on energetic particle precipitation into the ionosphere. Data from an excellent additional conjunction to NOAA 17 indicated that a latitudinally localized band of $30-80 \mathrm{keV}$ proton precipitation was observed at low Earth orbit collocated with the Cluster observations of EMIC waves at higher equatorial altitudes on the same field lines.

[33] Using this ground satellite conjunction, we were also able to test the hypothesis that EMIC wave packet modulation, as observed in Pc1 pearls such as those reported here, might be due to EMIC wave growth rate modulation by longer-period Pc5 ULF waves on the same field line. In this event, although we were able to clearly identify the local field line resonance mode, both on Cluster and on the ground, the fundamental frequency did not match the observed EMIC wave packet repetition period. Using the third standing field line mode eigenperiod, we estimated the EMIC wave propagation time (there and back) along the field line and found it to be in good agreement with the EMIC wave packet repetition period on the ground. For a short time during the time of conjunction, EMIC wave packets were observed every $65 \mathrm{~s}$ on Cluster and every $130 \mathrm{~s}$ on the ground, which suggests bidirectional propagation of EMIC wave packets in space. Together with the above estimate of the EMIC wave packet, travel time may be explained within the bouncing wave packet hypothesis or some similar theory [see Demekhov, 2007].

[34] Our observations support the earlier suggestion of Usanova et al. [2008] that magnetospheric compressions, during periods of enhanced solar wind dynamic pressure, could play an important role in the generation of EMIC waves in the inner magnetosphere, these waves being excited in a localized region just inside the plasmapause. This is consistent with the conclusion of Anderson and Hamilton [1993] that EMIC wave growth at higher $L$ shells was enhanced by the modest magnetospheric compression. 
[35] Our observations confirm that EMIC waves can cause the precipitation of energetic protons into the ionosphere. Many previous studies such as those of Sandanger et al. [2009], having inferred EMIC waves, might have been responsible for proton precipitation spikes inside the plasmapause observed at LEO but without any direct evidence of the hypothesized EMIC waves themselves. Interestingly, Sandanger et al. [2007] also report evidence that these proton precipitation events are often also collocated with regions of $\mathrm{MeV}$ energy electron precipitation from the radiation belts.

[36] Consequently, we suggest that compression-related EMIC waves such as those we reported here could also be responsible for the loss of particles from the radiation belts, as well as from the ring current. Future studies should continue to examine mechanisms for EMIC wave generation and the role of EMIC waves in the dynamics and loss of energetic ions in the ring current and electrons in the outer radiation belts during periods of magnetospheric compression occurring due to enhanced solar wind dynamic pressure.

[37] Acknowledgments. We thank J. H. King and N. E. Papitashvili for providing solar wind data, NASA/Goddard Space Flight Center for CDAWeb and SSCWeb facilities, the Kyoto World Data Center for provisional Dst data, H. J. Singer, NOAA SWPC, for the GOES 10 and 12 data, and CAA for the Cluster data. We acknowledge Kanji Hayashi, Martin Connors, and the Solar-Terrestrial Environment Program (STEP) Polar Network for Parksite, Lucky Lake, and Uzury magnetometer data. We would like to thank Swedish Institute of Space Physics and the Sodankylä Geophysical Observatory for making the quicklook magnetometer data available. We acknowledge the reviewers for their constructive comments. Z.C.K. wishes to thank F. W. Menk, C. L. Waters, and L. G. Ozeke for cross-phase and density inversion programs. M.U. was supported by NSERC Discovery grants to IRM and RDS. CARISMA is operated by the University of Alberta and funded by the Canadian Space Agency.

[38] Wolfgang Baumjohann thanks Howard Singer and Richard Denton for their assistance in evaluating this paper.

\section{References}

Anderson, B. J., and D. J. Hamilton (1993), Electromagnetic ion cyclotron waves stimulated by modest magnetospheric compressions, J. Geophys. Res., 98(A7), 11,369-11,382.

Balogh, A., et al. (2001), The Cluster Magnetic Field Investigation: overview of in-flight performance and initial results, Ann. Geophys., 19, 1207-1217.

Cornwall, J. M. (1965), Cyclotron instabilities and electromagnetic emissions in the ultra low frequency and very low frequency ranges, J. Geophys. Res., 70(A1), 61-69.

Demekhov, A. G. (2007), Recent progress in understanding Pc1 pearl formation, J. Atmos. Sol.-Terr. Phys., 69(14), 1609-1622.

Décréau, P. M. E., et al. (2001), Early results from the Whisper instrument on Cluster: an overview, Ann. Geophys., 19, 1241-1258.

Dent, Z. C., I. R. Mann, F. W. Menk, J. Goldstein, C. R. Wilford, M. A. Clilverd, and L. G. Ozeke (2003), A coordinated ground-based and IMAGE satellite study of quiet-time plasmaspheric density profiles, Geophys. Res. Lett., 30(12), 1600, doi:10.1029/2003GL016946.

Denton, R. E., J. LaBelle, and X. Zhu (2002), Location of Pc1-2 waves relative to the magnetopause, Ann. Geophys., 20, 1763-1767.

Erlandson, R. E., B. J. Anderson, and L. J. Zanetti (1992), Viking magnetic and electric field observations of periodic Pc1 waves: Pearl pulsations, J. Geophys. Res., 97(A10), 14,823-14,832.

Escoubet, C. P., M. Fehringer, and M. Goldstein (2001), The Cluster mission, Ann. Geophys., 19, 1197-1200.

Evans, D. S., and M. S. Greer (2000), Polar Orbiting Environmental Satellite Space Environment Monitor 2: Instrument description and archive data documentation, NOAA Tech.Memo.OAR SEC-93, NOAA, Boulder, Colo.

Fraser, B. J., J. C. Samson, Y. D. Hu, R. L. McPherron, and C.T. Russell (1992), Electromagnetic ion cyclotron waves observed near the oxygen cyclotron frequency by ISEE-1 and -2, J. Geophys. Res., 97(A3), 3063-3074.
Fraser, B. J., H. J. Singer, W. J. Hughes, J. R. Wygant, R. R. Anderson, and Y. D. Hu (1996), CRRES Poynting vector observations of electromagnetic ion cyclotron waves near the plasmapause, J. Geophys. Res., 101(A7), 15,331-15,343.

Gendrin, R. (1975), Is the plasmapause a preferential region for proton precipitation? Ann. Geophys., 31, 127

Gendrin, R., M. Ashour-Abdalla, Y. Omura, and K. Quest (1984), Linear Analysis of Ion Cyclotron Interaction in a Multicomponent Plasma, J. Geophys. Res., 89(A10), 9119-9124.

Gustafsson, G., et al. (2001), First results of electric field and density observations by Cluster EFW based on initial months of operation, Ann. Geophys., 19, 1219-1240.

Hansen, H. J., B. J. Fraser, F. W. Menk, Y.-D. Hu, P. T. Newell, C.-I. Meng, and R. J. Morris (1992), High-latitude Pc1 bursts arising in the dayside boundary layer region, J. Geophys. Res., 97(A4), 3993-4008.

Hayakawa, M., S. Shimakura, T. Kobayashi, and N. Sato (1992), A study of polarization of irregular pulsations of diminishing period and their generation mechanism, Planet. Space Sci., 40, 1081-1091.

Jacobs, J. A., and T. Watanabe (1964), Micropulsation whistlers, J. Atmos. Terr. Phys., 26, 825-829.

Jordanova, V. K., J. U. Kozyra, A. F. Nagy, and G. V. Khazanov (1997), Kinetic model of the ring current-atmosphere interactions, J. Geophys. Res., 102(A7), 14,279-14,291.

King, J. H., and N. E. Papitashvili (2004), Solar wind spatial scales in and comparisons of hourly wind and ACE plasma and magnetic field data, J. Geophys. Res., 110(A2), A02209, doi:10.1029/2004JA010804.

Kozyra, J. U., T. E. Cravens, F. Nagy, and E. G. Fontheim (1984), Effects of energetic heavy ions on electromagnetic ion cyclotron wave generation in the plasmapause region, J. Geophys. Res., 89(A4), 2217-2233.

Loto'aniu, T. M., B. J. Fraser, and C. L. Waters (2005), Propagation of electromagnetic ion cyclotron wave energy in the magnetosphere, J. Geophys. Res., 110(A7), A07214, doi:10.1029/2004JA010816.

Loto'aniu, T. M., B. J. Fraser, and C. L. Waters (2009), The modulation of electromagnetic ion cyclotron waves by Pc5 ULF waves, Ann. Geophys. 27, 121-130.

Mann, I. R., et al. (2008), The upgraded CARISMA magnetometer array in the THEMIS era, Space Sci. Rev., 141, 413-451.

Menk, F. W., B. J. Fraser, H. J. Hansen, P. T. Newell, C.-I. Meng, and R. J. Morris (1992), Identification of the magnetospheric cusp and cleft using Pc1-2 ULF pulsations, J. Atmos. Terr. Phys., 54, 1021-1042.

Mursula, K., R. Rasinkangas, T. Bösinger, R. Erlandson, and P.-A. Lindqvist (1997), Nonbouncing Pc1 wave bursts, J. Geophys. Res., 102(A8), $17,611-17,624$

Mursula, K., T. Bräysy, R. Rasinkangas, P. Tanskanen and F. Mozer (1999), A modulated multiband Pc1 event observed by POLAR/EFI around the plasmapause, Adv. Space Res., 24(1), 81-84, doi:10.1016/ S0273-1177(99)00429-9.

Mursula, K., T. Bräysy, K. Niskala, and C. T. Russell (2001), Pc1 pearls revisited: Structured electromagnetic ion cyclotron waves on Polar satellite and on ground, J. Geophys. Res., 106(A12), 29,543-29,553.

Olson, J. V., and L. C. Lee (1983), Pc1 wave generation by sudden impulses, Planet. Space Sci., 31, 295-302.

Parent, A., I. R. Mann, and K. Shiokawa (2007), Observing the MLT and L-shell dependence of ground magnetic signatures of the ionospheric Alfvén resonator, in Proceedings of the Eighth Conference on Substorms (ICS-8), edited by Syrjäsuo and Donovan, pp. 225-230, Univ. of Calgary, Alberta, Canada.

Paschmann, G., et al. (2001), The electron drift instrument on Cluster: Overview of first result, Ann. Geophys., 19, 1273-1288.

Pedersen, A., et al. (2001), Four-point high time resolution information on electron densities by the electric field experiments (EFW) on Cluster, Ann. Geophys., 19, 1483-1489.

Rae, I. J., et al. (2005), Evolution and characteristics of global Pc5 ULF waves during a high solar wind speed interval, J. Geophys. Res., 110(A12), A12211, doi:10.1029/2005JA011007.

Rasinkangas, R., and K. Mursula (1998), Modulation of magnetospheric EMIC waves by Pc3 pulsations of upstream origin, Geophys. Res. Lett., 25(6), 869-872.

Sandanger, M., F. Søraas, K. Aarsnes, K. Oksavik, and D. S. Evans (2007), Loss of relativistic electrons: Evidence for pitch angle scattering by electromagnetic ion cyclotron waves excited by unstable ring current protons, J. Geophys. Res., 112(A12), A12213, doi:10.1029/2006JA012138.

Sandanger, M., F. Søraas, M. Sørbø, K. Aarsnes, K. Oksavik, D. S. Evans (2009), Relativistic electron losses related to EMIC waves during CIR and CME storms, J. Atmos. Sol.-Terr. Phys., 71(10-11), 1126-1144.

Schulz, M. (1996), Eigenfrequencies of geomagnetic field lines and implications for plasma density modeling, J. Geophys. Res., 101(A8), 17,385-17,397.

Singer, H. J., L. Matheson, R. Grubb, A. Newman, and S. D. Bouwer (1996), Monitoring Space Weather with the GOES Magnetometers, in 
SPIE Conference Proceedings, 2812, GOES-8 and Beyond, edited by E. R. Washwell, pp. 299-308.

Søraas, F., J. A. Lundblad, N. F. Maltseva, V. Troitskaya, and V. Selivanov (1980), A comparison between simultaneous IPDP ground-based observations and observations of energetic protons obtained by satellites, Planet. Space Sci., 28(4), 387-405.

Southwood, D. J., and M. G. Kivelson (1981), Charged particle behavior in low-frequency geomagnetic pulsations: 1. Transverse waves, J. Geophys. Res., 86(A7), 5643-5655.

Summers, D., and R. M. Thorne (2003), Relativistic electron pitch angle scattering by electromagnetic ion cyclotron waves during geomagnetic storms, J. Geophys. Res., 108(A4), 1143, doi:10.1029/2002JA009489.

Summers, D., R. M. Thorne, and F. Xiao (1998), Relativistic theory of wave-particle resonant diffusion with application to electron acceleration in the magnetosphere, J. Geophys. Res., 103(A9), 20,487-20,500.

Tsyganenko, N. A. (1996), Effects of the solar wind conditions on the global magnetospheric configuration as deduced from data-based field models, in Proceedings of the ICS-3 Conference on Substorms, edited by E. J. Rolfe and B. Kaldeich, Eur. Space Agency Spec. Publ., ESA SP-389, 181-185.

Usanova, M. E., I. R. Mann, I. J. Rae, Z. C. Kale, V. Angelopoulos, J. W. Bonnell, K.-H. Glassmeier, H. U. Auster, and H. J. Singer (2008), Multipoint observations of magnetospheric compression-related EMIC Pc1 waves by THEMIS and CARISMA, Geophys. Res. Lett., 35(17), L17S25, doi:10.1029/2008GL034458.

Waters, C. L., J. C. Samson, and E. F. Donovan (1996), Variation of plasmatrough density derived from magnetospheric field line resonances, J. Geophys. Res., 101(A11), 24,737-24,745.
Wright, D. M., and T. K. Yeoman (1999), High resolution bistatic HF radar observations of ULF waves in artificially generated backscatter, Geophys. Res. Lett., 26(18), 2825-2828.

Yahnin, A. G., and T. A. Yahnina (2007), Energetic proton precipitation related to ion-cyclotron waves, J. Atmos. Terr. Phys., 69, 1690-1706.

Yahnin, A. G., T. A. Yahnina, A. G. Demekhov, J. Manninen, J. Kultima, and J. Kangas (2004), Multiple sources as a possible cause of multiband spectra of Pc1 geomagnetic pulsations, Geomagn. Aeron., 44(3), 288 291.

K.-H. Fornacon, Institut für Geophysik und Extraterrestrische Physik, Technische Universität Braunschweig, Pockelsstraße 14, 38106 Braunschweig, D-0531 391-0 Germany.

K.-H. Glassmeier, Max Planck Institute for Solar System Research, MaxPlanck-Str. 2, Katlenburg-Lindau, D-37191 Germany.

Z. C. Kale, I. R. Mann, I. J. Rae, R. D. Sydora, and M. E. Usanova, Department of Physics, University of Alberta, 11322-89 Avenue, Edmonton, Alberta T6G 2G7, Canada. (musanova@phys.ualberta.ca)

A. Masson, Research and Scientific Support Department, ESTEC Keplerlaan 1, Noordwijk, NL-2201 AZ, Netherlands.

H. Matsui and P. A. Puhl-Quinn, Space Science Center, University of New Hampshire, 8 College Road, Durham, NH 03824, USA.

M. Sandanger and F. Søraas, Department of Physics and Technology, University of Bergen, Allegaten 55, N-5007 Bergen, Norway.

$\mathrm{X}$. Vallières, Centre National de la Recherche Scientifique, Université d'Orléans, Laboratoire de Physique et Chimie de L'Environement, 3A Av. de la Recherche Scientifique, Orléans CEDEX 2, F-45071, France. 